http://dx.doi.org/10.1590/0104-1428.2180

\title{
Kinetic behavior of the reaction between silica and epoxidized liquid rubber
}

\author{
Marcus Vinícius Braum ${ }^{1 *}$ and Marly Antônia Maldaner Jacobi ${ }^{1}$
}

\author{
'Programa de Pós-graduação em Ciência dos Materiais, Instituto de Química, Universidade Federal do \\ Rio Grande do Sul - UFRGS, Porto Alegre, RS, Brazil \\ *marcus.braum@pirelli.com
}

\begin{abstract}
The use of epoxidized rubber as compatibilizer in silica-filled rubber compounds has been proposed in literature. However, the investigation of the reaction kinetics between the epoxy groups and the hydroxyl groups at the silica surface is not yet described. It is a difficult task, mainly because of the high dilution of the system due the difficulty of incorporating high levels of silica in a matrix containing epoxidized rubbers of high molecular weight. In this work, a mixture of precipitated silica and an epoxidized liquid rubber (EpLHPB) was prepared and the reaction between silanols and epoxy groups was followed by DSC under isothermal conditions, at 150,160 and $170{ }^{\circ} \mathrm{C}$. An autocatalytic data treatment was applied to determine the kinetic parameters of the reaction. Furthermore, it was possible to estimate the amount of epoxy groups required for the saturation of the external surface of the silica, resulting in 5.4 epoxy groups $/ \mathrm{nm}^{2}$.
\end{abstract}

Keywords: composites, epoxidized rubber, kinetics, silanols, silica.

\section{Introduction}

High-performance rubber materials are usually reinforced by colloidal filler such as silica or carbon black, in order to improve their mechanical properties. Due to the presence of siloxane and silanol polar groups on its surface, silica exhibits a high specific component of surface free energy. Consequently, the interactions between these polar groups and the nonpolar hydrocarbon rubbers are very weak compared with the hydrogen bonds that occur between the silanols, resulting in weaker polymer-filler interaction and greater tendency to agglomerate than carbon black. For this reason, bifunctional silanes such as bis-(triethoxysilylpropyl) tetrasulfide (TESPT) are commonly used to enhance compatibility of nonpolar rubbers with silica and improve mechanical properties of silica-filled elastomers, since such coupling agents are capable of establishing covalent bonds between polymer chains and silica surface ${ }^{[1,2]}$.

Despite its undeniable benefits, the use of silanes is not devoid of drawbacks. These include the formation of ethanol (a byproduct of the silanization reaction) and the processing difficulties of such compounds, whose mixing temperature range is narrow $\left(145-155^{\circ} \mathrm{C}\right)$ due to the need to ensure a sufficient silanization rate, while avoiding the risk of scorch. Because of such difficulties, rubber compounds containing silica in a high content often require the use of specially-designed mixers and three or more mixing stages ${ }^{[3,4]}$.

In order to avoid the drawbacks of the silanization process, the use of epoxidized rubber as an alternative to the use of silanes has been investigated ${ }^{[5-7]}$. Jacobi et al. ${ }^{[6]}$ showed that lightly-epoxidized cis-BR and silica can react during a reactive mixing process. However, attempts to study the kinetics of this reaction by DSC were unsuccessful, probably due to the high degree of dilution of the silica/epoxidized rubber system in such compounds ${ }^{[8]}$. Also using DSC technique, Wasantakorn ${ }^{[9]}$ successfully observed the occurrence of reaction between the epoxy groups of an epoxidized natural rubber (ENR) and hydroxyls of silicic acid, but without attempting to clarify any aspects of the kinetics of this reaction.

In this paper, a kinetic study with emphasis on phenomenological modeling is presented for the reaction between epoxy groups and silica, involving the use of an epoxidized liquid rubber. The low viscosity of this rubber allows the intrusion of some chains in the macro- and mesopores of the silica, favoring the impregnation of the filler and thus enhancing the contact between epoxidized polymer and silica surface. Thus the reaction kinetics of mixtures of highly dispersible silica (HD) with a liquid hydroxylated polybutadiene epoxidized at $8.8 \mathrm{~mol} \%$ (EpLHPB) was studied through isothermal experiments in DSC, from which it is possible to evaluate autocatalytic and nth order reactions ${ }^{[10,11]}$. In addition to the kinetic parameters of the reaction, the content of epoxide groups required for the saturation of the external surface of the silica could also be estimated.

\section{Materials and Methods}

\section{1 Materials}

The commercial silica utilized in this study, Zeosil 1165MP (Rhodia), was used without further purification. The silica presented a total specific surface of $139 \mathrm{~m}^{2} / \mathrm{g}$, determined by the BET method ${ }^{[12]}$, and an external specific surface of $113 \mathrm{~m}^{2} / \mathrm{g}$, determined by the t-plot method using the Lippens-de Boer equation ${ }^{[13]}$.

Liquid hydroxylated polybutadiene (LHPB) was supplied by Petroflex, now known as Lanxess (Brazil), and used in the condition it was received in. The sample presented a $\mathrm{Mn}=5400 \mathrm{~g} / \mathrm{mol}$, determined via GPC using THF as solvent, conventional calibration using PS, and detection 
by refractive index. The microstructure was determined via FTIR analysis by liquid film on $\mathrm{KBr}^{[14]}$, resulting in $20 \%$ of 1,2-vinyl conformation, $24 \%$ of 1,4 -cis and $56 \%$ of 1,4-trans.

EpLHPB was obtained and characterized in our laboratory, according to procedures similar to those described elsewhere ${ }^{[15]}$ : LHPB was epoxidized in a toluene solution at $44 \%(\mathrm{w} / \mathrm{w})$ at $50{ }^{\circ} \mathrm{C}$ for 6 hours via the method of the performic acid generated in situ, using stoichiometric molar ratio of the reactants $\left(\mathrm{H}_{2} \mathrm{O}_{2}: \mathrm{C}=\mathrm{C}: \mathrm{HCOOH}\right)$. The epoxy content was determined by ${ }^{1} \mathrm{H}$ NMR (300 MHz, $\mathrm{CDCl}_{3}$ ).

\subsection{Mixing procedure}

The mixing of the liquid rubber with the precipitated silica was performed by manual grinding in mortar and pestle for five minutes. EpLHPB/sílica samples were prepared in different proportions in order to obtain a different concentration of epoxide groups (available for reaction with silanol groups) per unit external surface of sílica, $Q_{E P O X}$, calculated from Equation 1:

$$
Q_{\text {epox }}=\frac{m_{E p L H P B} \times \alpha_{\text {epox }}}{\left[\alpha_{\text {epox }} \times M_{\text {epox }}+\left(100-\alpha_{\text {epox }}\right) \times M_{\text {olef }}\right] \times m_{\text {silica }} \times S_{E X T}}
$$

where $m_{E P L H P B}$ is the weight of epoxidized oligomer in the mixture, in grams, $\alpha_{E P O X}$ is the degree of epoxidation of the polymer, in mol\%, $M_{E P O X}$ and $M_{O L E F}$ are the molar masses of the epoxidized and olefinic units, respectively, $S_{E X T}$ is the specific external surface of the silica, in $\mathrm{m}^{2} / \mathrm{g}$, and $m_{\text {SILICA }}$ is the mass, in grams, of silica in the mixture. An example is given in Equation 2. By mixing $1.28 \mathrm{~g}$ of silica $\left(S_{E X T}=113 \mathrm{~m}^{2} / \mathrm{g}\right)$ and $1.00 \mathrm{~g}$ of EpLHPB $8.8 \mathrm{~mol} \%$ epoxidized, we have:

$$
Q_{\text {epox }}=\frac{1.0 \times 8.8}{[8.8 \times 70+91.2 \times 54] \times 1.28 \times 113}=11.0 \times 10^{-6} \mathrm{~mol} / \mathrm{m}^{2}
$$

\subsection{DSC analysis}

The differential scanning calorimetry studies were performed with a MDSC 2920 (TA Instruments, New Castle, DE, USA), using aluminum pans, under nitrogen flow. The dynamic scan was performed at a heating rate of $10{ }^{\circ} \mathrm{C} / \mathrm{min}$ from 25 to $250{ }^{\circ} \mathrm{C}$. Studies in isothermal scan mode were performed at temperatures of 150,160 and $170^{\circ} \mathrm{C}$.

The Standard E 2070 (Test Method A) was used in order to determine the kinetic parameters of the reaction. Differential scanning calorimetry has been widely used to develop cure kinetic models for thermoset matrices, assuming proportionality between the heat of the reaction completed $\left(\Delta \mathrm{H}_{C}\right)$ and the fraction converted $(\alpha)$ through the Equation 3:

$$
\alpha=\Delta H_{c} / \Delta H
$$

where $\Delta H$ is the total heat of the reaction. For each isothermal experiment, a linear baseline was constructed between the beginning and the end on the exotherm peak. The heat of the reaction $\Delta \mathrm{H}(\mathrm{J} / \mathrm{g})$ was then determined by integrating the total area of the peak bounded by the peak itself and the baseline constructed. After identifying the times corresponding to 10 and $90 \%$ of the peak area, at least 10 equally spaced time values were selected between these limits. Then, the rate of reaction $d H / d t(\mathrm{~W})$ and the heat of the reaction completed $\Delta \mathrm{H}_{C}(\mathrm{~J} / \mathrm{g})$ were obtained for each time interval, as illustrated in Figure 1.

The fractional rate of reaction $d \alpha / d t\left(\mathrm{~min}^{-1}\right)$ was determined from these data using Equation 4:

$$
d \alpha / d t=(d H / d t) / \Delta H
$$

When an isothermal process is characterized by a heat flow curve that reaches a maximum within seconds then slowly decays, an nth order reaction is probable. If the thermal curve instead shows a maximum after tens of seconds, as shown in Figure 1, an autocatalyzed reaction is likely to occur. An autocatalyzed reaction follows the relationship of Equation $5^{[16,17]}$ :

$$
d \alpha / d t=k(T) \alpha^{m}(1-\alpha)^{n}
$$

where $k(T)$ is the specific rate constant at temperature $T\left(\mathrm{~min}^{-1}\right)$ and $m, n$ are the partial reaction order terms. Also known as Sesták-Berggren equation, Equation 5 was originally applied to the kinetic of reactions in the solid state. ${ }^{[16]}$ In order to determine the kinetic parameters $k(T), m$ and $n$ for each temperature, Equation 5 was cast in its logarithmic form (Equation 6) and solved with a multiple linear regression using Data Analysis Tool of Microsoft Excel.

$$
\ln [d \alpha / d t]=\ln [k(T)]+m \ln [\alpha]+n \ln [1-\alpha]
$$

The change of $k(T)$ with temperature is described with the Equation 7, of Arrhenius ${ }^{[17]}$ :

$$
k(T)=Z e^{(-E / R T)}
$$

where $Z\left(\mathrm{~min}^{-1}\right)$ is the pre-exponential factor, $E(\mathrm{~J} / \mathrm{mol})$ is the activation energy, $R(8.314 \mathrm{~J} / \mathrm{K} . \mathrm{mol})$ is the gas constant and $T(\mathrm{~K})$ is the absolute temperature. Thus, the plot of $\ln [k(T)]$ versus $1 / \mathrm{T}$ is linear, with the slope equal to $-E / R$ and the intercept equal to $\ln [Z]$.

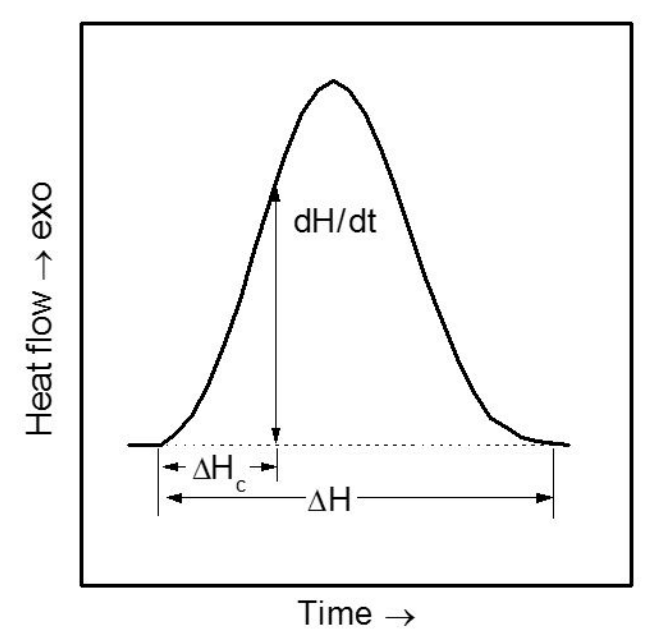

Figure 1. Typical DSC isotherm used to determine the total heat reaction, $\Delta \mathrm{H}$, the rate of reaction $d H / d t$ and heat of the reaction completed $\Delta \mathrm{H}_{C^{\prime}}$. 


\section{Results and Discussions}

In a preliminary experiment, a sample of silica impregnated with EpLHPB (1:1.28 by weight) was heated from 25 to $250{ }^{\circ} \mathrm{C}$ at $10{ }^{\circ} \mathrm{C} / \mathrm{min}$. In this experiment the appearance of an exothermic event was observed, whose onset temperature was $170{ }^{\circ} \mathrm{C}$. Thus, this temperature was selected to carry out the isothermal tests.

Figure 2 shows the isothermal heating runs at $170^{\circ} \mathrm{C}$ for: a LHPB/silica mixture, pure silica, pure EpLHPB ( $8.8 \mathrm{~mol} \%$ epoxidized), and a sample of silica impregnated with EpLHPB ( $1: 1.28$ by weight, $\left.Q_{E P O X}=11.0 \times 10^{-6} \mathrm{~mol} / \mathrm{m}^{2}\right)$ in the first and second heating runs.

The appearance of an exothermic event is clearly observed in the first heating run of the mixture EpLHPB/silica, which disappears in the second run (a new heating program, after a fast cooling until $25^{\circ} \mathrm{C}$ ). Moreover, this thermal event is

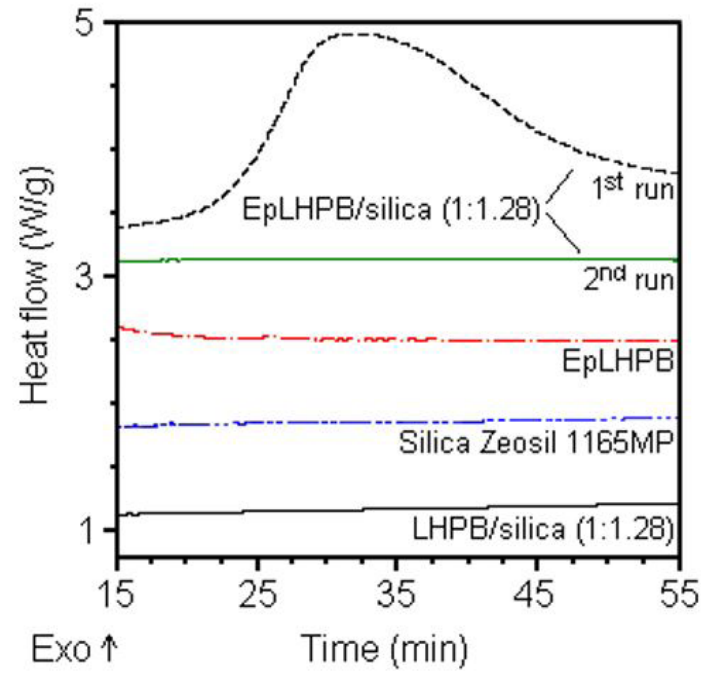

Figure 2. DSC curves of the mixture EpLHPB/silica $\left(Q_{E P O X}=11.0\right.$ $\times 10^{-6} \mathrm{~mol} / \mathrm{m}^{2}$ or weight ratio $\left.1: 1.28\right)$, pure ingredients and mixture LHPB/silica (weight ratio 1:1.28). The thermograms were obtained under nitrogen flow and isothermal conditions, at $170{ }^{\circ} \mathrm{C}$. not detected in the traces of the pure components and in the mixture of LHPB/silica in the same proportion. This is a strong indication that a reaction occurs between the epoxy groups of the EpLHPB and $\mathrm{OH}$ groups present on the silica surface. As mentioned in the introduction, previous studies $^{[9]}$ discuss this reaction without quantifying their kinetic parameters.

Figure 3 shows the DSC measurements in isothermal scan mode for silicas impregnated with EpLHPB containing different amounts of epoxy groups per unit of silica external surface. As can be seen, when $Q_{E P O X}$ is increased, the rate of the reaction silanol-epoxy is decreased and its onset is progressively retarded. Most likely this occurs as increasing the amount of liquid polymer in the mixture makes expelling the water adsorbed on the silica surface more difficult, hindering contact between the reactive groups. The results shown in Figure 4 validate this hypothesis, since pre-heating the impregnated silica at $105^{\circ} \mathrm{C}$ for $120 \mathrm{~min}$ led to a considerable decrease in onset time and a narrowing of the heat release curve.

In order to verify if this reaction may occur at lower temperatures, or if the moisture present in the silica could interfere with the process, the sample EpLHPB at $Q_{E P O X}=9.2 \times 10^{-6} \mathrm{~mol} / \mathrm{m}^{2}$ was pre-heated under vacuum at $105^{\circ} \mathrm{C}$ for $120 \mathrm{~min}$ and then analyzed. Figure 4 shows the behavior of the mixture with and without pre-heating. Notably, there is a substantial reduction in the time required for the occurrence of the maximum heat release: from 26 to $8 \mathrm{~min}$, while there was no substantial change in the heat of reaction with the pre-heating process. It is inferred that partial reaction during this process should not have occurred, or even the formation of intermediates. Thus, the phenomenon can be attributed to an improvement in the contact between polymer and silica, i.e. a better wettability facilitated by the elimination of the air and water physically adsorbed on the silica surface.

The heat of reaction $(\Delta \mathrm{H})$ is an extrinsic process and can be used as a parameter to monitor the extent of the reaction, allowing the stoichiometric ratio of the reaction system to be determined ${ }^{[18]}$. In Figure 5 the heats of reaction were plotted against the respective values of $Q_{E P O X}$, using the data determined in the Figure 3. It is noted that $\Delta \mathrm{H}$

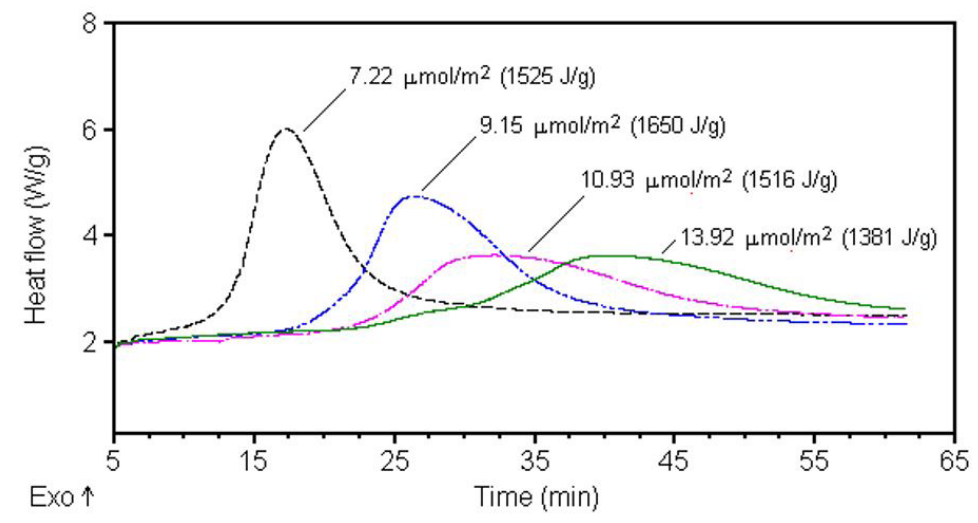

Figure 3. DSC curves of the mixture EpLHPB/silica in different proportions (curves are identified by the value of $Q_{E P O X}$ ). The thermograms were obtained under $\mathrm{N}_{2}$ flow and isothermal conditions, at $170^{\circ} \mathrm{C}$. 
initially rises, it reaches a maximum and then it decreases again. From the trend line drawn it was possible to obtain an estimated value for the stoichiometric ratio epoxy/silica, or point of saturation of the silica surface with epoxy groups, being approximately $9.0 \times 10^{-6} \mathrm{~mol} / \mathrm{m}^{2}$. Below this value there is probably an excess of silica in the mixture, while higher values indicate an excess of epoxy groups. The value determined for the point of saturation of the silica surface may also be expressed as 5.4 oxirane rings per $\mathrm{nm}^{2}$ of silica external surface, which is very close to the physicochemical constant of Kiselev-Zhuravlev ${ }^{[19]}\left(4.9 \pm 0.5 \mathrm{OH} / \mathrm{nm}^{2}\right)$, which describes the maximum density of silanol groups on a silica surface, regardless of its origin.

Shown in Figure 6 are the isothermal scans for the silica impregnated with EpLHPB $\left(Q_{E P O X}=9.2 \times 10^{-6} \mathrm{~mol} / \mathrm{m}^{2}\right)$, at 150,160 and $170{ }^{\circ} \mathrm{C}$. The samples were pre-heated under

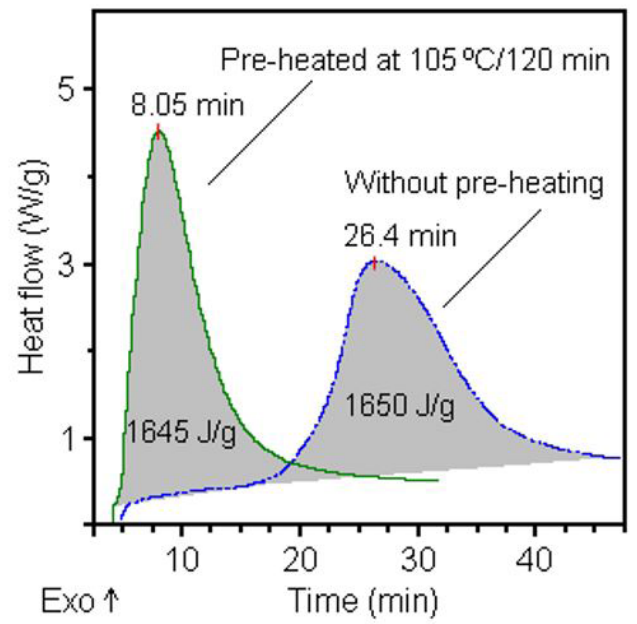

Figure 4. Isothermal DSC runs at $170{ }^{\circ} \mathrm{C}$ of a mixture silica/EpLHPB at $Q_{E P O X}=9.2 \times 10^{-6} \mathrm{~mol} / \mathrm{m}^{2}$, with and without pre-heating of the sample.

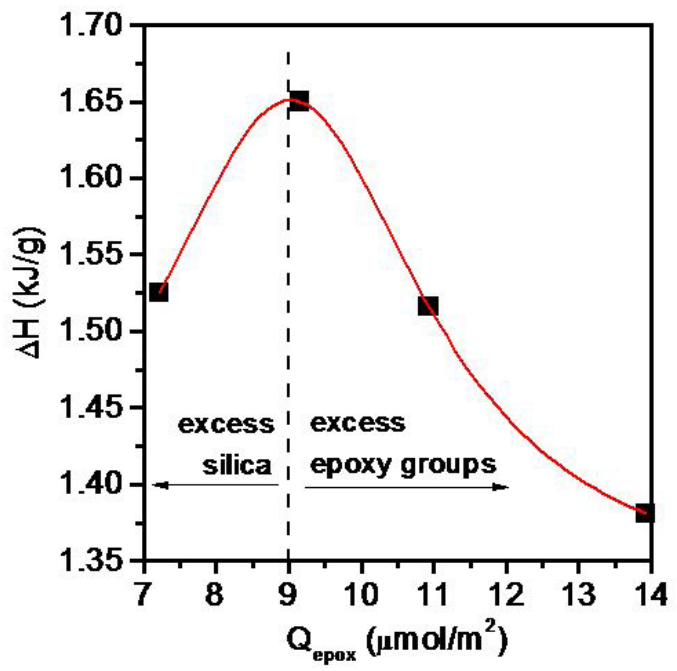

Figure 5. Heat of reaction $(\Delta \mathrm{H})$ as function of epoxy groups content per unit external surface of silica $\left(Q_{E P O X}\right)$, in $\mu \mathrm{mol} / \mathrm{m}^{2}$. Drawn from the data in Figure 3. vacuum at $105{ }^{\circ} \mathrm{C}$ for $120 \mathrm{~min}$ before being introduced into the DSC pans.

Observing the shapes of the thermal curves can be inferred that an autocatalyzed reaction is likely, since the heat flow curves build to a maximum after 8 to $22 \mathrm{~min}$. Instead, in an nth order reaction the heat flow curve would show a maximum within few seconds ${ }^{[17]}$. In autocatalytic processes the reaction product serves as an additional catalyst in the reaction, and the term $\alpha^{m}$ in Equation 5 account for this extra effect ${ }^{[20]}$.

The kinetic parameters obtained by applying the autocatalytic model are given in Table 1. The mechanism of the reaction between silica and epoxidized rubber does not seem to be the same over the entire temperature range, since the reaction orders are not constant ${ }^{[21]}$ : The kinetic exponent $n$ increases as a function of temperature, while the exponent $m$ remains almost constant.

A hypothetical mechanism of the silanol/epoxy reaction may involve nucleophilic attack on a carbon of the epoxy ring by a silanol group. At the beginning of the reaction, the reactive sites on the silica surface (silanols) are plentiful and the reaction of an epoxy group facilitates the approximation of neighboring groups, which could explain the observed autocatalytic effect. At this stage the reaction is kinetically controlled

In the course of the reaction, the reactive sites become scarce and sterically hindered, while the chain mobility gradually decreases due to the immobilization of chain segments on the silica surface. Similarly to the epoxy curing reactions, a diffusion-controlled process will probably occur at the onset of this vitrification process, when the kinetic reaction ends ${ }^{[20]}$.

At low temperatures, the process is expected to start with the reaction of a few epoxy groups per chain, before spreading. However, the rise in temperature can cause the process to be started with the reaction of many groups per chain. Thus, an increase in temperature should preferably

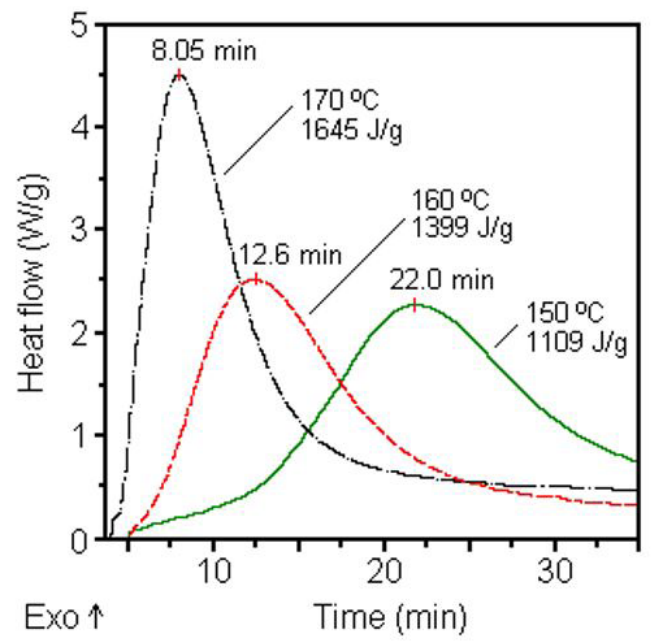

Figure 6. Isothermal DSC runs at 150,160 and $170^{\circ} \mathrm{C}$ of a mixture silica/EpLHPB at $Q_{E P O X}=9.2 \times 10^{-6} \mathrm{~mol} / \mathrm{m}^{2}$. The sample was pre-heated under vacuum at $105^{\circ} \mathrm{C}$ for $120 \mathrm{~min}$. 
Table 1. Kinetic parameters of the autocatalytic model obtained from isothermal analysis performed in DSC and data treatment according to ASTM E $2070^{[17]}$.

\begin{tabular}{ccccc}
\hline $\boldsymbol{T}(\mathbf{K})$ & $\boldsymbol{\operatorname { l n }}[\boldsymbol{k}(\boldsymbol{T})]\left(\ln \left[\mathbf{m i n}^{-1}\right]\right)$ & $\boldsymbol{m}$ & $\boldsymbol{E}$ & $\boldsymbol{E}(\mathbf{k J} / \mathbf{m o l})$ \\
\hline 423 & $-5.946 \pm 0.016$ & $0.65 \pm 0.01$ & $0.73 \pm 0.01$ & \\
433 & $-5.493 \pm 0.014$ & $0.62 \pm 0.01$ & $0.98 \pm 0.01$ & $82.4 \pm 8.0$ \\
443 & $-4.888 \pm 0.015$ & $0.56 \pm 0.01$ & $1.15 \pm 0.01$ & $17.4 \pm 2.2$ \\
\hline
\end{tabular}
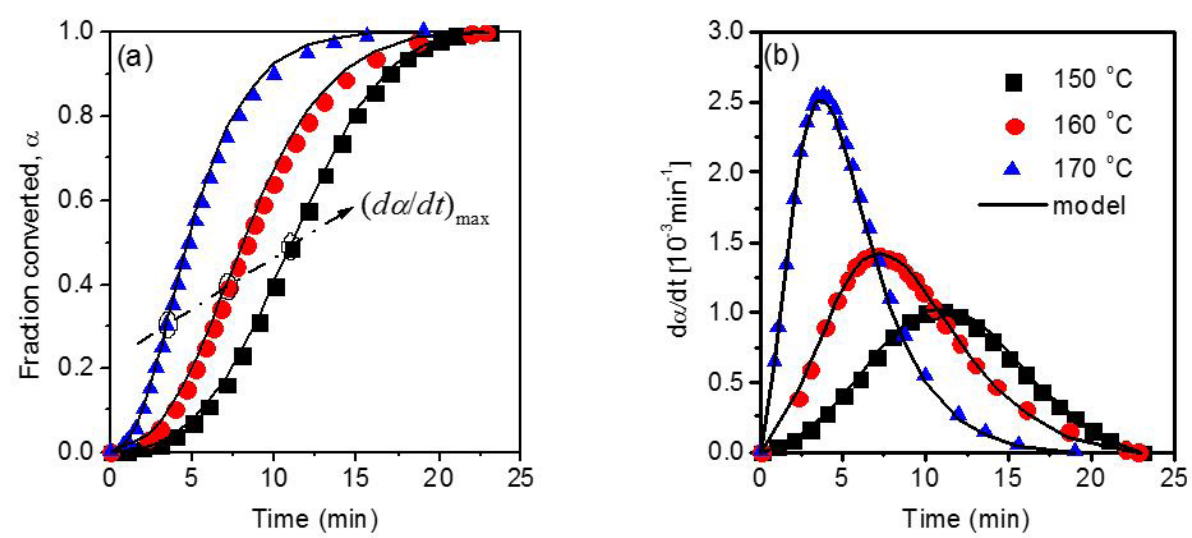

Figure 7. Fraction converted (a) and conversion rate (b) versus elapsed time after reaction onset for silica impregnated with EpLHPB $\left(Q_{E P O X}=9.2 \times 10^{-6} \mathrm{~mol} / \mathrm{m}^{2}\right)$ at 150,160 and $170^{\circ} \mathrm{C}$.

promote the initial process, kinetically controlled, resulting in faster chain immobilization and shifting the maximum in $d \alpha / d t$ to lower values of $\alpha$, as indicated in Figure 7. Such an increase of the contribution of the diffusional process to the overall kinetics can explain the increase in the exponent $n$ with temperature.

The experimental data and theoretical curves for the fraction converted and fractional rate of reaction are shown in Figure 7. The theoretical curves of $d \alpha / d t$ were calculated using the parameters $m, n$ and $k$ presented in Table 1, while the theoretical curves of $\alpha$ were obtained through the integration of the theoretical curves of $d \alpha / d t$ using the Origin software. There is a very good agreement between experimental data and theoretical fittings, supporting the interpretation proposed above.

The kinetic study showed that the process is very fast at $170^{\circ} \mathrm{C}$, which is very suitable as this temperature is within the usual range adopted for mixing processes (step of addition of fillers) and vulcanization in the rubber industry.

\section{Conclusions}

The kinetics of the chemical reaction occurred between EpLHPB and silica could be studied by DSC. It was possible to estimate the content of epoxy groups required for the saturation of a silica external surface: 5.4 oxiranes $/ \mathrm{nm}^{2}$, a value in close to the constant of Kiselev-Zhuravlev. The system presents features of an autocatalytic reaction and a reaction enthalpy of $1645 \mathrm{~kJ} / \mathrm{mol}$ at $443 \mathrm{~K}$. The kinetic parameters could be determined through isothermal scanning, making possible the generation of predictive curves of the reaction. This is very useful for the optimization of the reactive mixing process between silica and epoxidized rubber.

\section{References}

1. Byers, J. T. (2002). Fillers for balancing passenger tire tread properties. Rubber Chemistry and Technology, 75(3), 527-548. http://dx.doi.org/10.5254/1.3547681.

2. Vilgis, T., Heinrich, G., \& Klüppel, M. (2009). Reinforcement of polymer nano-composites: theory, experiments and applications. Cambridge: Cambridge University Press.

3. Dierkes, W. (2005). Economic mixing of silica-rubber compounds (Doctoral thesis). University of Twente, Enschede.

4. Luginsland, H.-D. (1999). Processing of the organo silane Si 69. In Proceedings of the RubberChem '99. Antwerp: Rapra.

5. Rocha, T. L. A. C., Schuster, R. H., Jacobi, M. M., \& Samios, D. (2004). Influence of epoxidation on physical properties of SBR and its interaction with precipitated silica. Kautschuk und Gummi, Kunststoffe, 57(12), 656-661. Retrieved in 17 April 2015, from http://www.kgk-rubberpoint.de/ai/resources/7bfb4c001c9. pdf

6. Jacobi, M. M., Braum, M. V., Rocha, T. L. A. C., \& Schuster, R. H. (2007). Lightly epoxidized polybutadiene with efficient interaction to precipitated silica. Kautschuk und Gummi, Kunststoffe, 60(9), 460-466. Retrieved in 17 April 2015, from http://www.kgk-rubberpoint.de/texte/anzeigen/718

7. Saramolee, P., Sahakaro, K., Lopattananon, N., Dierkes, W. K., \& Noordermeer, J. W. M. (2014). Comparative properties of silica- and carbon black-reinforced natural rubber in the presence of epoxidized low molecular weight polymer. Rubber Chemistry and Technology, 87(2), 320-339. http://dx.doi. org/10.5254/rct.13.86970.

8. Braum, M. V. (2006). Melhoria da interação polímero-carga através do uso de borracha de polibutadieno epoxidada (Master's dissertation). Universidade Federal do Rio Grande do Sul, Porto Alegre.

9. Wasantakorn, A. (2006). A Study on reaction of ENR with silicic acid. Journal of Research in Engineering and Technology, 3(1), 1-20. Retrieved in 17 April 2015, from http://anchan.lib. ku.ac.th/kukr/handle/ 003/19595 
10. Berglund, L. A., \& Kenny, J. M. (1991). Processing science for high performance thermoset composites. SAMPE Journal, 27(2), 27-37.

11. Nam, J., \& Seferis, J. C. (1993). Application of the kinetic composite methodology to autocatalytic-type thermoset prepreg cures. Journal of Applied Polymer Science, 50(9), 1555-1564. http://dx.doi.org/10.1002/app.1993.070500909.

12. Brunauer, S., Emmett, P. H., \& Teller, E. (1938). Adsorption of gases in multimolecular layers. Journal of the American Chemical Society, 60(2), 309-319. http://dx.doi.org/10.1021/ ja01269a023.

13. Lippens, B. C., \& de Boer, J. H. (1965). Studies on pore systems in catalysts: V. The $t$ method. Journal of Catalysis, 4(3), 319323. http://dx.doi.org/10.1016/0021-9517(65)90307-6.

14. Takahashi, M. F. K., \& Polito, W. L. (1997). Aplicações da espectroscopia de infravermelho com Transformada de Fourier para especiação isomérica de polibutadienos hidroxilados utilizados na síntese de polímeros PU-Propelentes. Polímeros: Ciência e Tecnologia, 7(1), 37-43. http://dx.doi.org/10.1590/ S0104-14281997000100007.

15. Rocha, T. L. A. C., Jacobi, M. M., Samios, D., Meier, J., \& Schuster, R. H. (2004). Study of the epoxidation of polydiene rubbers part III: Influence of epoxidation on viscoelastic behavior of SBR and BR melts. Kautschuk und Gummi, Kunststoffe, 57(7-8), 377-384. Retrieved in 17 April 2015, from http:// www.kgk-rubberpoint.de/texte/anzeigen/412

16. Sesták, J., \& Berggren, G. (1971). Study of the kinetics of the mechanism of solid-state reactions at increasing temperatures.
Thermochimica Acta, 3(1), 1-12. http://dx.doi.org/10.1016/00406031(71)85051-7.

17. American Society for Testing and Materials-ASTM. (2000). ASTM E2070-00: standard test method for kinetic parameters by differential scanning calorimetry using isothermal methods. West Conshohocken: ASTM International.

18. González-Garcia, F., Miguez, E., \& Soares, B. G. (2005). Characterization of diglycidyl ether of bisphenol A / aliphatic polyamines systems. Polímeros: Ciência e Tecnologia, 15(4), 261-267. http://dx.doi.org/10.1590/S0104-14282005000400010.

19. Zhuravlev, L. T. (2000). The surface chemistry of amorphous silica. Colloids and Surfaces. A, Physicochemical and Engineering Aspects, 173(1-3), 1-38. http://dx.doi.org/10.1016/S09277757(00)00556-2.

20. Bilyeu, B., Brostow, W., \& Menard, K. P. (2001). Epoxy thermosets and their applications III. Kinetic equations and models. Journal of Materials Education, 23(4-6), 189-204. Retrieved in 17 April 2015, from http://www.unt.edu/ LAPOM/ publications/pdf\%20articles/Lisa/epoxyJME3.pdf

21. Kenny, J. M. (1994). Determination of autocatalytic kinetic model parameters describing thermoset cure. Journal of Applied Polymer Science, 51(4), 761-764. http://dx.doi.org/10.1002/ app.1994.070510424. 